\title{
Prevalence of Hyperthyroidism and its Impact on Quality of Life Among Students of the Islamia University of Bahawalpur Pakistan
}

\author{
Shifa Shaffique ${ }^{1, *}$, Haseeb Anwer ${ }^{1}$, Hafiz Muhammad Asif ${ }^{2}$, Imran ul Haq ${ }^{3}$, Muhammad Akram \\ ${ }^{1}$ Department of Physiology, Faculty of Life Sciences, Government College University, Faisalabad, Pakistan \\ ${ }^{2}$ University College of Conventional Medicine, Faculty of Pharmacy and Alternative Medicine, The Islamia \\ University of Bahawalpur, Pakistan \\ ${ }^{3}$ Consultant Endocrinologist, Diabetologist\& Internist, South City Hospital, Karachi, Pakistan \\ ${ }^{4}$ Department of Eastern Medicine, Government College University, Faisalabad, Pakistan
}

\section{ABSTRACT}

Authors' Contributions

1, 2, 3 Conception \& study design

1, 2, 4, 5 Data Collection \& Processing

1, 2, 4, 5 Data Analysis and/or interpretation

1, 2, 4, 5 Drafting of Manuscript

3 Critical Review

\section{Acknowledgement \\ The authors are thankful to Dr. Imran ulHaq, who is treating many patients of \\ hyperthyroidism in South City Hospital, Karachi. The first author is an example of successful treatment of hyperthyroidism during the time of this experiment. The authors have strongly recommended the participants with this disease to get treatment from Dr. Imran ulHaq.}

\section{Article info. \\ Received: March 30, 2020 \\ Accepted: September 25, 2020 \\ Funding Source: Nil \\ Conflict of Interest: Nil \\ Cite this article: Shaffique $\mathrm{S}$, Anwer $\mathrm{H}$, Asif HM, Haq I, Akram M. Prevalence of hyperthyroidism and its impact on quality of life among students of The Islamia University of Bahawalpur Pakistan. RADS J Pharm Pharm Sci. 2020; 8(2):85-90}

*Address of Correspondence Author: shifa.shafiquee@gmail.com
Aim: Population based studies on prevalence of hyperthyroidism and its impact on quality of life, with variability of weight, height and distribution, their associated symptoms are limited. Knowledge and awareness about the prevalence of hyperthyroidism and their associated symptoms and its treatment option is necessary for the patient education and evaluation of underlying causative factors of this disease.

Methodology: Apopulation-based study was conducted from October 2018 to May 2019 to determine the prevalence of hyperthyroidism and its impact on quality of life among the students of The Islamia University Bahawalpur. Questioner were developed and distributed among the consenting participants. Thirty-six males and one hundred and six females were included in this study.

Results: Our study concluded that prevalence of hyperthyroidism is $\mathrm{n}=10(6.6 \%)$ and its prevalence ishigher in middle class families. Hyperthyroidism has a positive link with family history and previous history as shown in the results i.e. $n=8(5.3 \%)$ with family history and $n=5(3.3 \%)$ linked with previoushistory. It is the leading cause of morbidity and its prevalence is raised day by day. We studied that hyperthyroidism produces following effects on quality of life; $n=10(6.6 \%)$ participants were presented with loss of concentration in work / studies=10 (6.6\%) with body ache, $n=8(5.3 \%)$ with social isolation, $n=10(6.6 \%)$ with mental health changes, $n=6(4 \%)$ with a history of previous treatment, $n=8(5.3 \%)$ with need of repeated checkups.

Conclusion: It is concluded from present study that the hypehyperthyroidism significantly affects the quality of life and it is positively linked with the family history and history.

Keywords: Hyperthyroidism, QoL, IUB 


\section{INTRODUCTION}

Hyperthyroidism is defined as a condition in which the thyroid produces an excessive amount of thyroxin [13]. Hyperthyroidism can hasten your metabolism, causing sudden loss of weight, a feeling of rapid or irregular heartbeat enlargement of thyroid, heat intolerance, diarrhea, sweating, hand tremors, nervousness or irritability [4-6].

Hyperthyroidism is due complex relation between genetic predisposition and environmental triggers such as amount of iodine intake and extent of smoking [7-9]. This diseased condition is also defined by suppressed serum level of TSH and increased concentrations of the thyroid hormone I.e. thyroxin and/or triiodothyronine [10-12]. Regardless of its cause I.e. Graves' disease or nodular toxic goiter, hyperthyroidism is linked with conditions such as: Atrial fibrillation, Stroke Pulmonary embolism, Hypercoagulopathy. These conditions could lead to an increased mortality rate [13-14]. The types of hyperthyroidism are Toxic multi-nodular goiter, Thyroid adenoma, Hyperthyroidism in pregnancy, lodine-induced hyperthyroidism, Hyperthyroidism in aging, Atrial fibrillation with hyperthyroidism, and Diabetes mellitus with hyperthyroidism [15-17]. Sometimes, simple goiters become multi-nodular over 10-20 years $[18,19]$. These nodules grow at irregular rates and become toxic and secrete thyroid hormone 'freely', thereby control TSH -dependent growth and function in the resting gland $[20,21]$. Very large goiter may cause stridor, difficulty in swallowing and superior vena cava obstruction. Grave's disease, the most typical form of hyperthyroidism, is an autoimmune disease in which antibodies called thyroid-stimulating immune-globulins (TSIs) form against the TSH receptor in the thyroid gland [22-24]. These antibodies attach with the same membrane receptors that attach $\mathrm{TSH}$ and generate continual stimulation of the CAMP system of the cells, with resultant spread of hyperthyroidism $[24,25]$.

The aim of cross sectional survey is to educate the females and males to give awareness about their treatment options, due to poor knowledge and misunderstanding among males and females and to find the prevalence of this disease and its impact on quality of life of people and this survey is conducted to collect the unbiased data from specific number of population and to develop sensible decisions based on analyzed results.

\section{METHODOLOGY}

The presentcross-sectionalsurvey was carried out from October 2018 to May 2019, after consent from ethical committee of The Islamia University Bahawalpur. Standard questionnaires were developed and distributed in consenting females and males total 150 participants were chosen for study. The participants were guaranteed that their data remain confidential and will be used only for research goal. Participants were guided to complete the questioner attentively. The questioner were prepared with reference to previous papers with slight modifications [26-29].

\section{DevelopmentofQuestionnaire:}

The first part of questioner accommodates personal information i.e. Name,father or husband name, age, sex, marital status, date, contact number, patient ID, address. The second part of questioner accommodates patient's history about Hyperthyroidism present/absent, BMI, BMR, Social status, residence. Patient previous history, family history and history of experience of recurrence in past.

The third part of questioner accommodates associated symptoms of hyperthyroidism i.e., heartbeat, fatigue, nervousness, weak memory, voice changes, hair fall, mood changes, blurry or double vision, eye red, dry, swollen, tremors of extremities, weight changes, goiter, diabetes associated with hyperthyroidism, any history of irregular, skipped, shorter or lighter, longer periods, blood pressure, and appetite. The fourth part of questioner accommodates impact of hyperthyroidism on daily life i.e. loss of concentration in work/studies, body ache, social isolation, need repeated checkups, mental health, limited physical activity, general health, sexual life, holidays, any history of taking drugs, alcohol, any history of smoking, any history of previous treatment and medications.

\section{Distribution of Questionnaires}

The questionnaire was developed and distributed in consenting females and males. A total of 150 participants were chosen for study. The participants were guaranteed that their data will use only for research goal. Part0020 icipants were guided to complete the questioner attentively. 


\section{Collection of Questionnaire}

We collected the questionnaires and we said that we are grateful for their cooperation.

\section{RESULTS}

Table 1. Participant's demographics.

\begin{tabular}{|c|c|c|}
\hline \multirow{3}{*}{ Gender } & Male & Female \\
\cline { 2 - 3 } & 44 & 106 \\
\cline { 2 - 3 } & $30 \%$ & $70 \%$ \\
\hline \multirow{3}{*}{ Marital Status } & Married & Unmarried \\
\cline { 2 - 3 } & 32 & 118 \\
\cline { 2 - 3 } & $21.5 \%$ & $78.5 \%$ \\
\hline \multirow{3}{*}{ Hyperthyroidism } & Present & Absent \\
\cline { 2 - 3 } & 10 & 140 \\
\cline { 2 - 3 } Residence & $6.6 \%$ & $93.3 \%$ \\
\cline { 2 - 3 } & Rural area & Urban area \\
\cline { 2 - 3 } & 45 & 105 \\
\hline
\end{tabular}

In our study, there were $\mathrm{n}=44(30 \%)$ having male and $\mathrm{n}=106(70 \%)$ having females, $\mathrm{n}=32(21 \%)$ were married and $\mathrm{n}=118$ (78\%) were unmarried, $\mathrm{n}=11$ (73\%) having hyperthyroidism and $\mathrm{n}=139$ (92\%) having no hyperthyroidism, and $\mathrm{n}=45(30 \%)$ were from rural area and $n=105$ (70\%) from urban area as shown in Table 1.

Table 2. Participant's Social Status.

\begin{tabular}{|c|c|c|}
\hline Social Status & Number & Percentage \\
\hline Upper class & 12 & $8 \%$ \\
\hline Middle class & 128 & $85.3 \%$ \\
\hline Lower class & 10 & $6.6 \%$ \\
\hline
\end{tabular}

Table 2 expresses the social status. The participants $\mathrm{n}=12(8 \%)$ were belonging to upper class, $\mathrm{n}=128$ (85.3\%) from middle class, $n=10 \quad(6.6 \%)$ were belonging to lower class.

In our study $n=8(5.3 \%)$ were with family history of hyperthyroidism and $n=2(1.3 \%)$ were not present with the history of hyperthyroidism. $n=5$ (3.3\%) were with previous history of hyperthyroidism and $n=5$ (3.3\%) were not with the previous history. Also, In our study $n=5(3.3 \%)$ had recurrence of hyperthyroidism and $n=5(3.3 \%)$ had no recurrence of hyperthyroidism as can be seen in Table $\mathbf{3}$.
Table 3. Participant's hyperthyroidism history.

\begin{tabular}{|c|c|c|}
\hline \multirow{3}{*}{ Family History } & Yes & No \\
\cline { 2 - 3 } & 8 & 2 \\
\cline { 2 - 3 } & $5.3 \%$ & $1.3 \%$ \\
\hline \multirow{2}{*}{ Previous History } & 5 & 5 \\
\cline { 2 - 3 } & $3.3 \%$ & $3.3 \%$ \\
\hline \multirow{2}{*}{ Recurrence } & 5 & 5 \\
\cline { 2 - 3 } & $3.3 \%$ & $3.3 \%$ \\
\hline
\end{tabular}

Table 4. Associated symptoms of the hyperthyroidism.

\begin{tabular}{|c|c|c|}
\hline Symptoms & Present & Percentage \\
\hline Heartbeat & 6 & $4 \%$ \\
\hline Fatigue & 6 & $4 \%$ \\
\hline Nervousness & 11 & $7.3 \%$ \\
\hline Memory loss & 11 & $7.3 \%$ \\
\hline Voice changes & 10 & $6.6 \%$ \\
\hline Hair fall & 10 & $6.6 \%$ \\
\hline Mood changes & 10 & $6.6 \%$ \\
\hline Blurry/double vision & 10 & $6.6 \%$ \\
\hline Red eye & 9 & $6 \%$ \\
\hline Tremors of extremities & 9 & $6 \%$ \\
\hline Weight changes & 4 & $2.6 \%$ \\
\hline Goiter & 9 & $6 \%$ \\
\hline $\begin{array}{c}\text { Diabetes associated with } \\
\text { hyperthyroidism }\end{array}$ & 8 & $5.3 \%$ \\
\hline Irregular periods & 9 & $6 \%$ \\
\hline
\end{tabular}

Table 4 summarize the associated symptoms of the hyperthyroidism in our study. $n=6(4 \%)$ were with irregular heartbeat, $n=6(4 \%)$ with fatigue, $n=11$ $(7.3 \%)$ with nervousness, $\mathrm{n}=11$ (7.3\%) with memory loss, $n=10(6.6 \%)$ presented with voice changes, $n=10$ $(6.6 \%)$ with mod changes, $n=10(6.6 \%)$ presented with hair fall, $\mathrm{n}=10(6.6 \%)$ from the complaints of blurry or double vision, $n=9(6 \%)$ with eyes red,dry, swollen, $n=9(6 \%)$ with tremors of extremities, $n=4$ $(2.6 \%)$ with weight changes, $n=9(6 \%)$ with goiter, $n=$ 8 (5.3) withdiabetes associated with hyperthyroidism, $n=9(6 \%)$ from the complaints of irregular, skipped, shorter, lighter, and longer periods. 
Table 5. Physical generals of the participants.

\begin{tabular}{|c|c|c|}
\hline Symptoms & Present & Percentage \\
\hline Anemia & 8 & $5.3 \%$ \\
\hline Jaundice & 2 & $1.3 \%$ \\
\hline Edema & 3 & $2 \%$ \\
\hline Cyanosis & 2 & $1.3 \%$ \\
\hline Koilonychias & 0 & $0 \%$ \\
\hline Clubbing & 0 & $0 \%$ \\
\hline Another & 0 & $0 \%$ \\
\hline
\end{tabular}

In our study $\mathrm{n}=8$ (5.3\%) were with anemia, $\mathrm{n}=2$ $(1.3 \%)$ with jaundice, $n=3(2 \%)$ with edema, $n=2$ $(1.3 \%)$ with cyanosis, $n=0(0 \%)$ with koilonychias, $n=0$ $(0 \%)$ with clubbing.

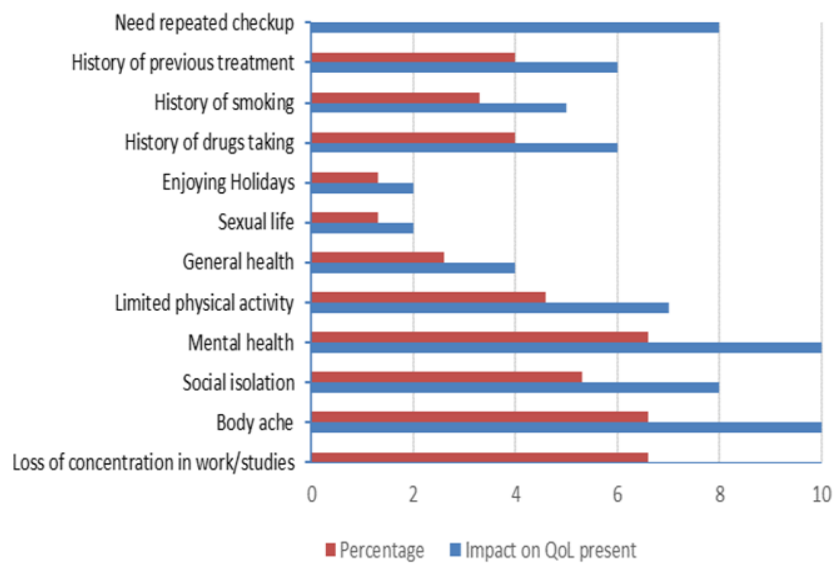

Figure 1. Impact of hyperthyroidism on quality of life.

In our study $\mathrm{n}=10(6.6 \%)$ with loss concentration in work/study, $n=10(6.6 \%)$ with Body ache, $n=8(5.3 \%)$ with social isolation, $\mathrm{n}=10(6.6 \%)$ with mental health, $\mathrm{n}=7(4.6 \%)$ with limited social health, $\mathrm{n}=4(2.6 \%)$ with general health, $n=2(1.3 \%)$ with sexual life, $n=2(1.3 \%)$ from complaints in holidays, $n=6(4 \%)$ with a history of drug taking, $n=5(3.3 \%)$ with a history of smoking, $\mathrm{n}=6(4 \%)$ with a history of previous treatment, $\mathrm{n}=$ $8(5.3 \%)$ with need repeated checkup.

\section{DISCUSSION}

Hyperthyroidism is the endocrinological disorder that involves various organs of the body and leads to serious clinical manifestation [30, 31]. Hyperthyroidism is the main cause of morbidity which affects the quality of life, globally the incidence of the disease increases with passage of the time so it is the need of the hour to find out the factors responsible for the association and causation [32, 33]. We conducted a short cross sectional study October 2018 -May 2019 for prevalence of hyperthyroidism and its impact on quality of life with various parameters to compute the linkage between association and the causation [34]. In this cross-sectional study, we took 150 participants with $n=44(30 \%)$ participants were males and $\mathrm{n}=106(70 \%)$ were females. Among these participants $\mathrm{n}=32(21 \%)$ were married and $\mathrm{n}=118(78 \%)$ were unmarried. It has been found out that $n=10(6.6 \%)$ participants were having hyperthyroidism and $\mathrm{n}=140(93.3 \%)$ participants were not presented with hyperthyroidism.

In our study, the results revealed that hyperthyroidism has positive link with family history as shown $\mathrm{n}=8(5.3 \%)$ i.e. out of 10 participants, 8 participants showed the family history of hyperthyroidism and this shows that if any person have family history of hyperthyroidism the chances of developing the disease increases. Similarly, hyperthyroidism has positive link with past history as shown $n=5(3.3 \%)$ i.e. there are $50 \%$ chances for a person to develop hyperthyroidism if he/she had any past history of hyperthyroidism in family,so it is recommended if a person with past history or genetic predisposition of the hyperthyroidism must have regular checkup and observation of symptoms, if it left untreated it may leads to serious complications.

\section{CONCLUSION}

The prevalence of hyperthyroidism in our study-based result is $6.6 \%$. We concluded from our study that hyperthyroidism is positively linked with family history and previous history and due to this chance of developing hyperthyroidism increases in a person who has any family history/previous history. It also affects the quality of life and it is the leading cause of morbidity. Our study also concluded that if once in a lifetime a person develops hyperthyroidism then chances of recurrence of disease increased to $50 \%$ and prevalence of hyperthyroidism is more in middle class family i.e. $n=128(85.3 \%)$. The prevalence of hyperthyroidism is $n=10(6.6 \%)$ this shows that prevalence of hyperthyroidism is significant. So, treatment option should be planned and educate the people to improve the quality of life with underlying disease l.e. regular checkup, observation of symptoms and to get proper treatment as directed by the physician. 


\section{RECOMMENDATION}

We concluded from the present study the prevalence of hypothyroidism is $6.6 \%$ and its impact on quality of life. As our sample size was small and our crosssectional study was limited. So, we recommend that the study should be conducted on the standard level with a big sample size so we could get more knowledge about this disease and its prevalence. In this way we could aware the people more accurately about this disease. Also, a better medicinal system should be introduced for the treatment ofhyperthyroidism andan alternativesystem of medicine i.e. homoeopathic system of medicine should be introduced for the treatment of hyperthyroidism.

\section{REFERENCES}

1. Franklyn JA. The management of hyperthyroidism. New England Journal of Medicine. 1994;330(24):1731-8.

DOI: $10.1056 /$ NEJM199406163302407

2. Reid JR, Wheeler SF. Hyperthyroidism: diagnosis and treatment. American family physician. 2005;72(4):623-30.

3. Bartalena L, Marcocci C, Bogazzi F, Manetti L, Tanda ML, Dell'Unto E, et al. Relation between therapy for hyperthyroidism and the course of Graves' ophthalmopathy. New England Journal of Medicine. DOI: 10.1056/NEJM199801083380201

4. Ferretti N, Yee J. Thyroid Storm: Glands Gone Wild! Case Studies in Emergency Medicine: Springer; 2020. p. 563-74.

5. Lakatos PA, Bakos B, Takacs I, Stern PH. Thyroid hormone and bone. Principles of Bone Biology: Elsevier; 2020. p. 895-914.

6. Association AT, Hyperthyroidism AAoCETo, Thyrotoxicosis OCo, Bahn RS, Burch HB, Cooper DS, et al. Hyperthyroidism and other causes of thyrotoxicosis: management guidelines of the American Thyroid Association and American Association of Clinical Endocrinologists. Thyroid. 2011;21(6):593-646. DOI: 10.1089/thy.2010.0417

7. Spaulding SW, Lippes H. Hyperthyroidism. Causes, clinical features, and diagnosis. The Medical clinics of North America. 1985;69(5):93751. DOI: 10.1016/s0025-7125(16)30998-1

8. Léger J, Carel JC. Hyperthyroidism in childhood: causes, when and how to treat. Journal of clinical research in pediatric endocrinology. 2013;5(Suppl 1):50.

9. Alberti L, Proverbio MC, Costagliola S, Weber G, Beck-Peccoz P, Chiumello $G$, et al. A novel germline mutation in the TSH receptor gene causes non-autoimmune autosomal dominant hyperthyroidism. European journal of endocrinology. 2001;145(3):249-54.

10. Kobayashi R, Shimomura Y, Otsuka M, Popov KM, Harris RA. Experimental hyperthyroidism causes inactivation of the branched-chain a-ketoacid dehydrogenase complex in rat liver. Archives of biochemistry and biophysics. 2000;375(1):55-61. https://doi.org/10.1006/abbi.1999.1635

11. Spanheimer RG, Bar RS, Hayford JC. Hyperthyroidism caused by inappropriate thyrotropin hypersecretion: studies in patients with selective pituitary resistance to thyroid hormone. Archives of internal medicine. 1982;142(7):1283-6. DOI: 10.1001/archinte.142.7.1283

12. Gershengorn M, Weintraub B. Thyrotropin-induced hyperthyroidism caused by selective pituitary resistance to thyroid hormone. A new syndrome of. The Journal of clinical investigation. 1975;56(3):633-42.

DOI: $10.1172 / \mathrm{JCl} 108133$

13. Ahmed R. Hyperthyroidism and developmental dysfunction. Arch Med. 2017;9(4):6. DOI: 10.21767/1989-5216.1000227.

14. Taylor PN, Albrecht D, Scholz A, Gutierrez-Buey $G$, Lazarus $J H$, Dayan $\mathrm{CM}$, et al. Global epidemiology of hyperthyroidism and hypothyroidism. Nature Reviews Endocrinology. 2018;14(5):301.

DOI: $10.1038 /$ nrendo.2018.18

15. Osuna PM, Udovcic M, Sharma MD. Hyperthyroidism and the Heart. Methodist DeBakey cardiovascular journal. 2017;13(2):60. doi: $10.14797 / \mathrm{mdcj}-13-2-60$

16. Journy NM, Bernier M-O, Doody MM, Alexander $\mathrm{BH}$, Linet MS, Kitahara CM. Hyperthyroidism, hypothyroidism, and cause-specific mortality in a large cohort of women. Thyroid. 2017;27(8):100110. DOI: $10.1089 /$ thy .2017 .0063

17. Kyriacou A, Kyriacou A, Syed AA, Perros P. Weight gain with hyperthyroidism therapy: a prospective pilot study. InSociety for Endocrinology BES 20182018 (Vol. 59). BioScientifica. https://doi.org/10.1111/cob.12328

18. Hurley DL, Gharib $H$. Evaluation and management of multinodular goiter. Otolaryngologic Clinics of North America. 1996;29(4):527-40.

19. Delange F, Hershman J, Ermans AM. Relationship between the serum thyrotropin level, the prevalence of goiter and the pattern of iodine metabolism in Idjwi Island. The Journal of Clinical Endocrinology \& Metabolism. 1971;33(2):261-8. DOI: 10.1210/jcem-33-2-261

20. Adams D, Kennedy T, Choufoer J, Querido A. Endemic goiter in Western New Guinea. III. Thyroid-stimulating activity of serum from severely iodine-deficient people. The Journal of Clinical Endocrinology \& Metabolism. 1968;28(5):685-92. DOI: 10.1210/jcem-28-5-685

21. Boukis $M$, Koutras D, Souvatzoglou A, Evangelopoulou A, Vrontakis M, Moulopoulos S. 
Thyroid hormone and immunological studies in endemic goiter. The Journal of Clinical Endocrinology \& Metabolism. 1983;57(4):859-62. DOI: $10.1210 /$ jcem-57-4-859

22. Weetman AP. Graves' disease. New England Journal of Medicine. 2000;343(17):1236-48. DOI: 10.1056/NEJM200010263431707

23. Brent GA. Graves' disease. New England Journal of Medicine. 2008;358(24):2594-605. DOI: 10.1056/NEJMcp0801880

24. Smith TJ, Hegedüs L. Graves' disease. New England Journal of Medicine. 2016;375(16):155265.

DOI: $10.1056 /$ NEJMra1510030

25. Nguyen CT, Mestman JH. Graves' hyperthyroidism in pregnancy. Current Opinion in Endocrinology, Diabetes and Obesity. 2019;26(5):232-40. DOI: 10.1097/MED.0000000000000492

26. Watt $T$, Hegedüs L, Groenvold M, Bjorner JB, Rasmussen ÅK, Bonnema SJ, et al. Validity and reliability of the novel thyroid-specific quality of life questionnaire, ThyPRO. European Journal of Endocrinology. 2010;162(1):161-7. DOI: 10.1530/EJE-09-0521

27. Canaris GJ, Manowitz NR, Mayor G, Ridgway EC. The Colorado thyroid disease prevalence study. Archives of internal medicine. 2000;160(4):526-34. DOI: 10.1001/archinte.160.4.526

28. Lamm SH, Braverman LE, Li FX, Richman K, Pino $S$, Howearth G. Thyroid health status of ammonium perchlorate workers: a cross-sectional occupational health study. Journal of Occupational and Environmental Medicine. 1999;41(4):248-60. DOI: 10.1097/00043764-199904000-00006

29. Crevenna R, Zettinig $G$, Keilani M, Posch M, Schmidinger M, Pirich $C$, et al. Quality of life in patients with non-metastatic differentiated thyroid cancer under thyroxine supplementation therapy. Supportive care in cancer. 2003;11(9):597-603. DOI: 10.1007/s00520-003-0474-4

30. Boelaert K, Visser WE, Taylor PN, Moran C, Léger $\mathrm{J}$, Persani L. Management of hyperthyroidism and hypothyroidism. Endocrinology. 2020;183:G33-G9.

31. Niedziela M, editor Hyperthyroidism in adolescents. 22nd European Congress of Endocrinology; 2020: BioScientifica.

32. Rivas AM, Pena C, Kopel J, Dennis J, Nugent K. Hypertension and hyperthyroidism: association and pathogenesis. The American Journal of the Medical Sciences. 2020.

33. Cooper DS, Samuels MH. Hyperthyroidism and Dementia. Thyroid. 2020;30(5):648-50.

34. Kitahara CM, de Vathaire F, Boutron-Ruault M-C, Journy N. Thyroid dysfunction and cancer incidence: a systematic review and meta-analysis. Endocrine-Related Cancer. 2020;27(4):245-59. DOI: 10.1530/ERC-19-0417

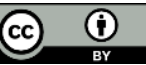

This is an Open Access article distributed under the terms of the Creative Commons Attribution License (http://creativecommons.org/licenses/by/4.0), which permits unrestricted use, distribution, and reproduction in any medium, provided the original work is properly cited. 